\title{
IT'S ALL MY FAULT, OR THE BEANSTALK SUCKS
}

\section{Scope for improvement.}

\section{BY IAN RANDAL STROCK}

$\mathrm{I}$ f'm wrong, and somebody should actually be around to find this, I want it known that it's my fault. Not the first disaster - I didn't start the nuclear war, and I doubt anyone who's left knows who did - but the second disaster, the more catastrophic one, that's me.

I guess I was lucky to be in Quito when the world nuked itself. Apparently, the Beanstalk wasn't a target on anyone's 'A' list. Either that, or whoever it was an A for got hit first and didn't get their turn.

Those people who talked about nuclear winter had it right - and I'm sure they'd be glad to know that. All those blasts creating all that debris, and all the fires, and atmospheric havoc, and whatnot... well, on a good day, I can see for metres. It's all that schmutz in the air. We can't see anything, and the Sun can't warm the planet.

I know, I know. If you're human, you know all this, as you were here for it. But if I'm right, and Fermi was wrong, maybe you're not from this planet, so I'm explaining it for you.

Anyway, once before I died (and I was wondering whether it would be the radiation or freezing - who knew?), I wanted to see the Sun again. I'm not sure why, I guess it's that feeling of the 'life-giving' Sun.

Like I said, Quito didn't take any direct hits, so most of the factories were still operational. Of course, the fallout from the near misses was enough to wipe out the population. Fortunately (or maybe, now, unfortunately), the Beanstalk's Control Room is a concrete-and-lead bunker a klick underground. Me, Sanchez and Johnston were on duty at the time, so we survived. There wasn't any food in the Control Room, so after a few days, I went out for a recon mission.

A flying brick had smashed the elevator's motor, as I found out when I got topside, so I had to hike up.

I couldn't find any food that had the least possibility of being safe to eat, but I figured we wouldn't last much longer anyway, and irradiated food was better than starving. While I was wandering around, seeing the remains of a recently vibrant city, I kept

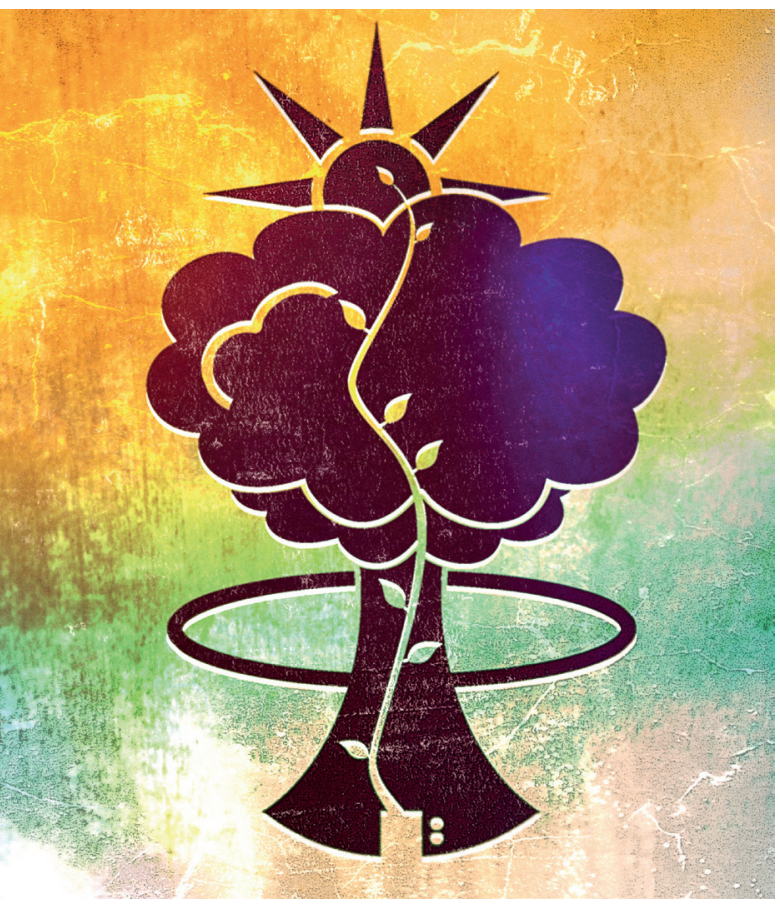

make the longest, and last, reflecting telescope in history.

Transporting the whole assembly to the Beanstalk was a bit of a problem, but once I got it there, hooking the canister to the CLM was a cinch.

Down to the Control Room I went, and then up the Beanstalk the canister, pulling its tube, went.

I headed for the surface, and the mirror I'd left at the base of my rising telescope. It looked like a vine growing on a tree.

I got to the base of the telescope about the same time the CLM reached the blockage up top. I saw the tube stop rising, and knew the mirror on top of the canister was opening.

There was about a klick of tube left, so I hacked through it, and tied the end down to keep it taut. Then I angled my eyepiece-mirror up the tube and looked. The Sun shined on my face, and I smiled. I felt better knowing that, even if the world was basically gone, the Sun was still there.

looking up, searching for the Sun. I think that's when I decided I wanted to see it one more time.

Anyway, I climbed back down to tell Sanchez and Johnston that our prospects for food weren't good, but when I opened the door, I realized that neither of them wanted to live in what was left of the world ... what a mess.

The diagnostics said there was an obstruction 150 klicks up, but I figured that would be high enough to get out of the gunk in the atmosphere. There was only one Cargo Lift Module available, but one was all I'd need.

I found a plastics factory, and figured out how to work the controls; thank goodness for automation. I set the machines to make a tube ... a long tube ... 1 metre in diameter, and 150 kilometres in length.

While the factory was busy extruding, I built a canister that was open on one end, which would be the bottom, and had a mirror sealed to the inside of the top. I was able to make the seal tight with rubber and

ONATURE.COM Follow Futures:

\section{y @NatureFutures}

$f$ go.nature.com/mtoodm sealant. A latch to open the top when it stopped moving, and I was ready to attach the plastic tube - and
I felt the beginning of a breeze that quickly got stronger. It was weird - I didn't remember feeling much air movement when I was out earlier.

It kept growing, and I realized it was blowing up my telescope. I stared at it stupidly for a few minutes, feeling the wind grow, and then something in my head said 'suction pump'.

I ran down to the Control Room, but there was no way I could get the CLM to come back down - it was fouled in whatever had stopped it. Naturally, I hadn't bothered to install a closing mechanism on the canister.

I know I was going to die anyway, but there may be some people somewhere who had a chance. Who were properly shielded. What do I say now? Whoever fired the bombs probably killed off most of the human race, but there had to be some remnant left.

But now, when we run out of air ...

The whistling's getting louder.

Ian Randal Strock is an author of two previous Futures, a winner of two AnLab Awards from Analog, and the publisher of Fantastic Books (www.FantasticBooks.biz). See everything Ian at www.IanRandalStrock.com. 